\title{
The PROPEL Electrodynamic Tether Demonstration Mission
}

\author{
Sven G. Bilén ${ }^{*}$ \\ The Pennsylvania State University, University Park, PA 16802 \\ C. Les Johnson, ${ }^{\dagger}$ Bruce M. Wiegmann, ${ }^{\ddagger}$ and Leslie Alexander ${ }^{\S}$ \\ Marshall Space Flight Center, Huntsville, AL 35758 \\ Brian E. Gilchrist ${ }^{* *}$ \\ The University of Michigan, Ann Arbor, MI 48109 \\ Robert P. Hoyt ${ }^{\dagger \dagger}$ \\ Tethers Unlimited, Inc., Bothell, WA 98011 \\ Craig H. Elder ${ }^{*}$ and Keith P. Fuhrhop ${ }^{\S \S}$ \\ Northrop Grumman Corporation, Redondo Beach, CA 90278 \\ Michael Scadera ${ }^{* * *}$ \\ Millennium Space Systems, Torrance, CA 90503 \\ and \\ Nobie Stone $\mathrm{i}^{\dagger \dagger}$ \\ Nexolve, Inc., Huntsville, AL 35806
}

\begin{abstract}
The PROPEL ("Propulsion using Electrodynamics") mission will demonstrate the operation of an electrodynamic tether propulsion system in low Earth orbit and advance its technology readiness level for multiple applications. The PROPEL mission has two primary objectives: first, to demonstrate the capability of electrodynamic tether technology to provide robust and safe, near-propellantless propulsion for orbit-raising, de-orbit, plane change, and station keeping, as well as to perform orbital power harvesting and formation flight; and, second, to fully characterize and validate the performance of an integrated electrodynamic tether propulsion system, qualifying it for infusion into future multiple satellite platforms and missions with minimal modification. This paper provides an overview of the PROPEL system and design reference missions; mission goals and required measurements; and ongoing PROPEL mission design efforts.
\end{abstract}

\footnotetext{
Assoc. Professor of Engineering Design, Electrical Engineering, and Aerospace Engineering, 213 Hammond Bldg., AIAA Associate Fellow.

Deputy Manager, Advanced Concepts Office (ED04), AIAA Member.

* Aerospace Engineer, Advanced Concepts Office (ED04).

$\S$ Technology Development and Integration Lead, Flight Programs and Projects Office (FP30), AIAA Member.

** Professor of Electrical Engineering and Space Science, 1301 Beal Ave., AIAA Associate Fellow.

$\dagger$ CEO \& Chief Scientist, 11711 North Creek Parkway South, Suite D-113, AIAA Senior Member.

* Spacecraft Project Manager, One Space Park, AIAA Member.

$\S \S$ Systems Engineer, One Space Park, Bldg. R5-2281B, AIAA Senior Member.

**** Director of Engineering, 20410 Earl St., AIAA Senior Member.

ti Chief Scientist, Aerospace Technologies Div., 655 Discovery Dr. 


\section{Introduction}

$\mathrm{L}$ ed by NASA Marshall Space Flight Center, a team from government, industry, and academia has developed a flight demonstration mission concept of an integrated tethered satellite system called PROPEL: "Propulsion using Electrodynamics". PROPEL will demonstrate the operation of an electrodynamic tether (EDT) propulsion system in low Earth orbit (LEO). The PROPEL mission has two primary objectives: (1) to demonstrate the capability of EDT technology to provide robust and safe, near-propellantless propulsion for orbit-raising, de-orbit, plane change, and station keeping, as well as to perform orbital power harvesting and formation flight; and (2) to fully characterize and validate the performance of an integrated EDT propulsion system, significantly advancing its TRL and qualifying it for infusion into future multiple satellite platforms and missions with minimum modification.

The exponential increase of launch system size - and cost - with delta- $\mathrm{V}$ makes missions that require large total impulses cost prohibitive. The PROPEL mission will demonstrate a fundamentally different method for generating thrust (using an EDT) to overcome the limitations of the rocket equation and perform new classes of missions currently unaffordable or infeasible. EDTs compare favorably to other electric propulsion schemes in that they provide both high-thrust-to-power and extremely high specific impulse $\left(I_{\mathrm{sp}}\right)$ performance, exceeding the fundamental limits of propellant-based electric propulsion (see Figure 1). This will allow missions to be performed that require very large delta-V's using much smaller, affordable systems.

EDT propulsion generates Lorentz force thrust through the interaction between a current driven along a conducting tether and a planetary magnetic field, using the planet itself as reaction mass, rather than an expelled propellant. The basic physics of EDTs has been successfully

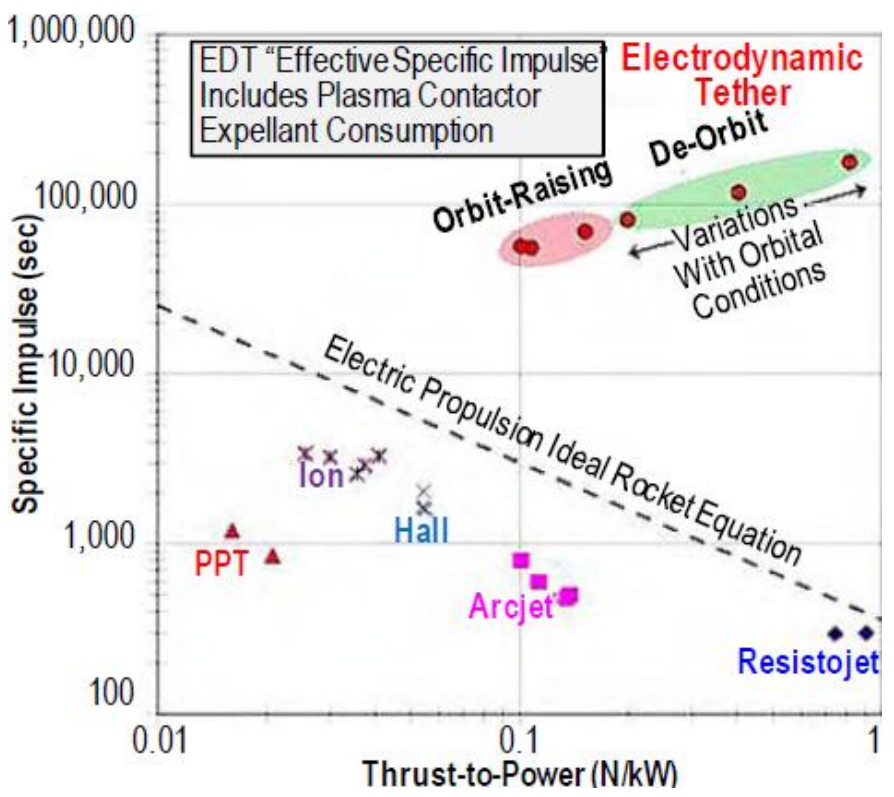

Figure 1. Comparison of electric propulsion technologies. EDTs provide both high-thrust-to-power and extremely high specific impulse performance, exceeding the fundamental limits of propellant-based electric propulsion. validated by prior flight experiments, but these experiments did not demonstrate orbital maneuvering. PROPEL will fly two instrumented satellites connected by a moderate length tether to demonstrate EDT orbital maneuvering. Hence, PROPEL will operationally validate a relevant EDT propulsion system, significantly advancing its TRL to 8, preparing it for direct infusion into future NASA, other government, and even commercial missions to provide game-changing and cross-cutting capabilities to undertake new, more ambitious missions such as persistent operations in very low Earth orbit (LEO) for ionospheric science and Earth observation, orbital debris removal, orbital maneuvering, drag make-up, and even orbit capture and power generation for future missions at Jupiter and the gas giants.

In this paper, we provide background information on EDT propulsion (Section II), followed by an overview of the PROPEL spacecraft and a design reference mission (Section III). We then discuss PROPEL's mission goals driving important questions that should be addressed and required measurements (Section IV). Ongoing PROPEL mission design efforts are overviewed (Section V), followed by some concluding remarks (Section (VI). An Appendix provides selected historical information on other tether missions. ${ }^{\$ \sharp}$

\section{Electrodynamic Tether Propulsion}

As illustrated in Figure 2, EDT propulsion generates Lorentz force thrust through the interaction between a current driven along a conducting tether and a planetary magnetic field, using the planet itself as reaction mass rather than the expelled propellant. In general, EDTs apply three key principles that govern their operation: $\left.{ }^{3} 1\right)$ the conductor has an intrinsic electromotive force $(\mathrm{emf})$ generated along it due to the orbital motion of the tether across

$\$$ Portions of this paper are from Ref. 1. 
the magnetic field, 2) the conductor provides a low-resistance path connecting different regions of the ionosphere, and 3) access to external electron and ion currents is confined to specific locations, such as the endpoint when the conductor is insulated, or collected along a length of bare tether. ${ }^{4}$

Current flows through the tether when a connection is made between the tether's endpoints and the surrounding ionospheric plasma, which can be accomplished via passive or active means. In the passive case, the voltages and currents in the overall system distribute themselves in a selfconsistent manner, which can require the endpoints to charge to high levels in order to attract enough current. Active means generally employ an electron generator of some type, such as a hollow cathode plasma contactor (HCPC) or an electron gun. Future tether systems may employ field emitter array cathodes (FEACs) ${ }^{5}$ but much work remains before FEACs are practicable for EDT systems. With either connection method, current flows through the tether as shown in Figure 1. In the EDT boost propulsion case, current flows down the tether because a high voltage source has overcome the motion-induced $\mathbf{v} \times \mathbf{B}$ electric field in the tether. After electrons are collected at the lower satellite (typical for a west-to-east Earth launch), they are conducted through the tether to the upper satellite where they are ejected. Current closure occurs in the ionosphere, thus making the overall circuit complete. The resulting $\mathbf{J} \times \mathbf{B}$ force is in a direction such as to pull the tether. Thrust levels depend directly on magnitude of the current flow and tether length - and are typically less than $1 \mathrm{~N}$.

The drag, or de-boost, case does not require the high voltage source (though it can be used to achieve enhanced current levels) and, as such, is often referred to as the generator mode, in which energy to drive the current is extracted from the spacecraft orbit. In this case the current flows up the tether, resulting in a $\mathbf{J} \times \mathbf{B}$ drag force. This configuration also allows for energy-harvesting, in which the tether current may be driven through other electrical loads (e.g., resistors, flywheels, batteries). ${ }^{6}$ It is important to note that this configuration can be used to de-orbit spacecraft at end of life, as has been proposed. ${ }^{7,8}$

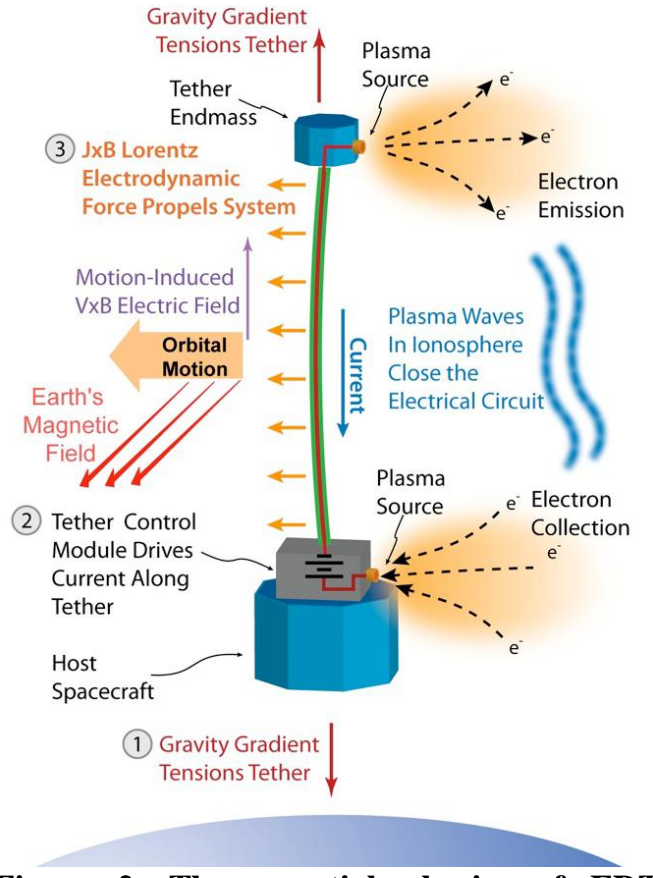

Figure 2. The essential physics of EDT propulsion. An EDT system generates thrust using interaction between current driven along a tether and the magnetic field of the planet it orbits, enabling propulsion without expelling propellant (from Ref. 2).

For more details and additional theory behind EDTs and EDT propulsion systems, refer to Refs. 1-4.

\section{PROPEL General System and Mission Description}

PROPEL was designed with multiple users in mind and to be flexible with respect to platform. To this end, the design team defined a set of mission objectives, detailed in Table I, to establish EDT propulsion ready for operational use.

\section{General PROPEL System Overview}

Figure 3 illustrates the general PROPEL system architecture. In this case, the PROPEL space vehicle consists of the Host Side (HS) spacecraft and Endmass (EM) spacecraft separated by a 3-km tether with the HS at the lower altitude. The EDT propulsion hardware consists of a 3-km conducting, multi-string tether with a tether deployer on the EM. The reel-type deployer has deployment and retrieval operational flight heritage with the two Tethered Satellite System (TSS) missions. HCPCs on both the host and EM are used for electrical contact with the ionosphere. 
PROPEL tether deployment will be monitored by on-board cameras, accelerometers, and tensiometers. The tether and deployment system also includes cutters and retractors on each side to enhance system safety in the event of a severed tether. The tether diagnostic hardware will provide tether dynamics, electrodynamic performance, and ambient ionospheric and PROPEL-induced plasma environments measurements. Measurement correlations will establish a theoretical basis for extrapolating performance to a broad range of space conditions and applications. The Langmuir probe provides reliable electron data at the boom tip. The hemispherical RPA offers a wide angle integrated ion flux measurement. To determine ion energy and density requires angle-of-incidence information provided by the Deflection Plate Analyzer (DPA).

\section{PROPEL's Design Reference Mission}

PROPEL's Design Reference Mission (DRM) operational profile (Figure 4) is designed to demonstrate the necessary EDT operational readiness objectives during a six-month mission life. PROPEL's multi-step demonstration approach provides operational capability data in a characterized plasma environment to validate operational EDT propulsive systems.

DRM Phases 1-3: PROPEL launches into a 500-km circular orbit. This altitude provides very good environmental plasma

Table I. PROPEL will demonstrate capabilities that will enable new missions.

\begin{tabular}{|c|c|}
\hline PROPEL Objective & Capability Enabled \\
\hline $\begin{array}{l}\text { System-level } \\
\text { demonstration of EDT } \\
\text { propulsion delivering high } \\
\text { thrust-to-power and large } \\
\text { total impulse for LEO } \\
\text { maneuvering and station } \\
\text { keeping }\end{array}$ & $\begin{array}{l}\text { - Low-mass systems to produce large } \Delta V \text {, } \\
\text { reducing launch vehicle size and total life- } \\
\text { cycle costs for many future missions } \\
\text { - Highly efficient orbital maneuvering and } \\
\text { plane change of LEO spacecraft } \\
\text { - Long-duration, low-LEO drag makeup of } \\
\text { large space systems }\end{array}$ \\
\hline $\begin{array}{l}\text { Accurately predict, verify, } \\
\text { and control EDT orbital } \\
\text { maneuvering, and validate } \\
\text { simulation and modeling } \\
\text { tools }\end{array}$ & $\begin{array}{l}\text { - Multiple precise orbital maneuvers and } \\
\text { rendezvous with small, affordable systems } \\
\text { - Long duration precision station keeping } \\
\text { - Predictive control ensures flight safety }\end{array}$ \\
\hline $\begin{array}{l}\text { Demonstrate orbital } \\
\text { energy harvesting }\end{array}$ & $\begin{array}{l}\text { - High burst power with lower mass and } \\
\text { cost } \\
\text { - Power generation at the outer planets } \\
\text { without RTGs }\end{array}$ \\
\hline $\begin{array}{l}\text { Validate survival and } \\
\text { operation of a conducting } \\
\text { tether for an extended } \\
\text { period }\end{array}$ & $\begin{array}{l}\text { - Tether performance data over a long } \\
\text { mission duration will enable extrapolation } \\
\text { to extended periods }\end{array}$ \\
\hline
\end{tabular}

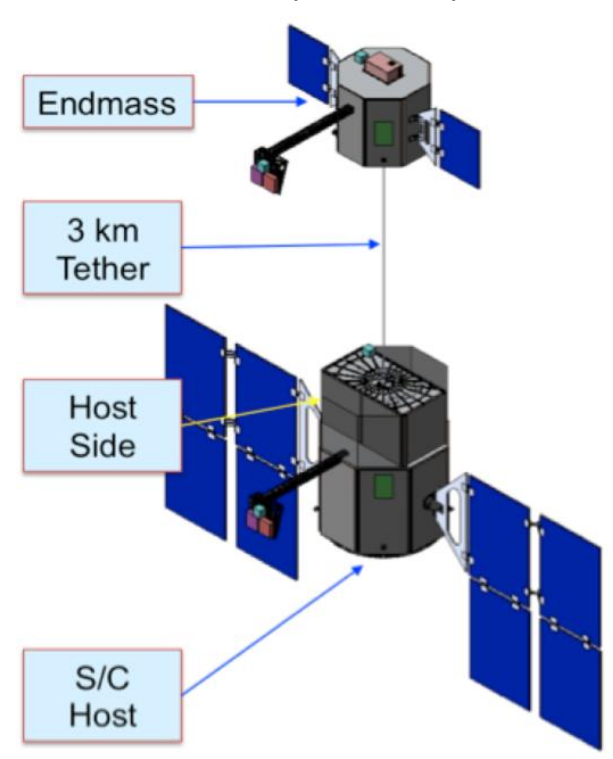

Figure 3. PROPEL consists of two spacecraft connected by a 3-km conducting tether.

conditions for the demonstration (e.g., ionospheric plasma electrical conductivity). A 500-km insertion also allows for a complete system checkout and tether deployment at an altitude above the International Space Station (ISS) orbit, and provides for a slow passive decay in case of an operational anomaly. Tether deployment will be initiated after solar array deployment, HS and EM checkout, instrument boom deployment, and HS-EM separation.

DRM Phases 4-13: PROPEL will demonstrate full EDT propulsive capabilities by raising the orbit from 500 $\mathrm{km}$ to $650 \mathrm{~km}$ after tether deployment and initial characterization. Diagnostic instruments are mounted on each endbody and allow the propulsive performance to be correlated with the surrounding space plasma environment. Following validation, the existing analytic performance models will be used to predict EDT performance to support mission operations. Subsequent mission phases include deboost/power generation, inclination change, precision orbital maneuvering, drag make-up, and deorbit. 


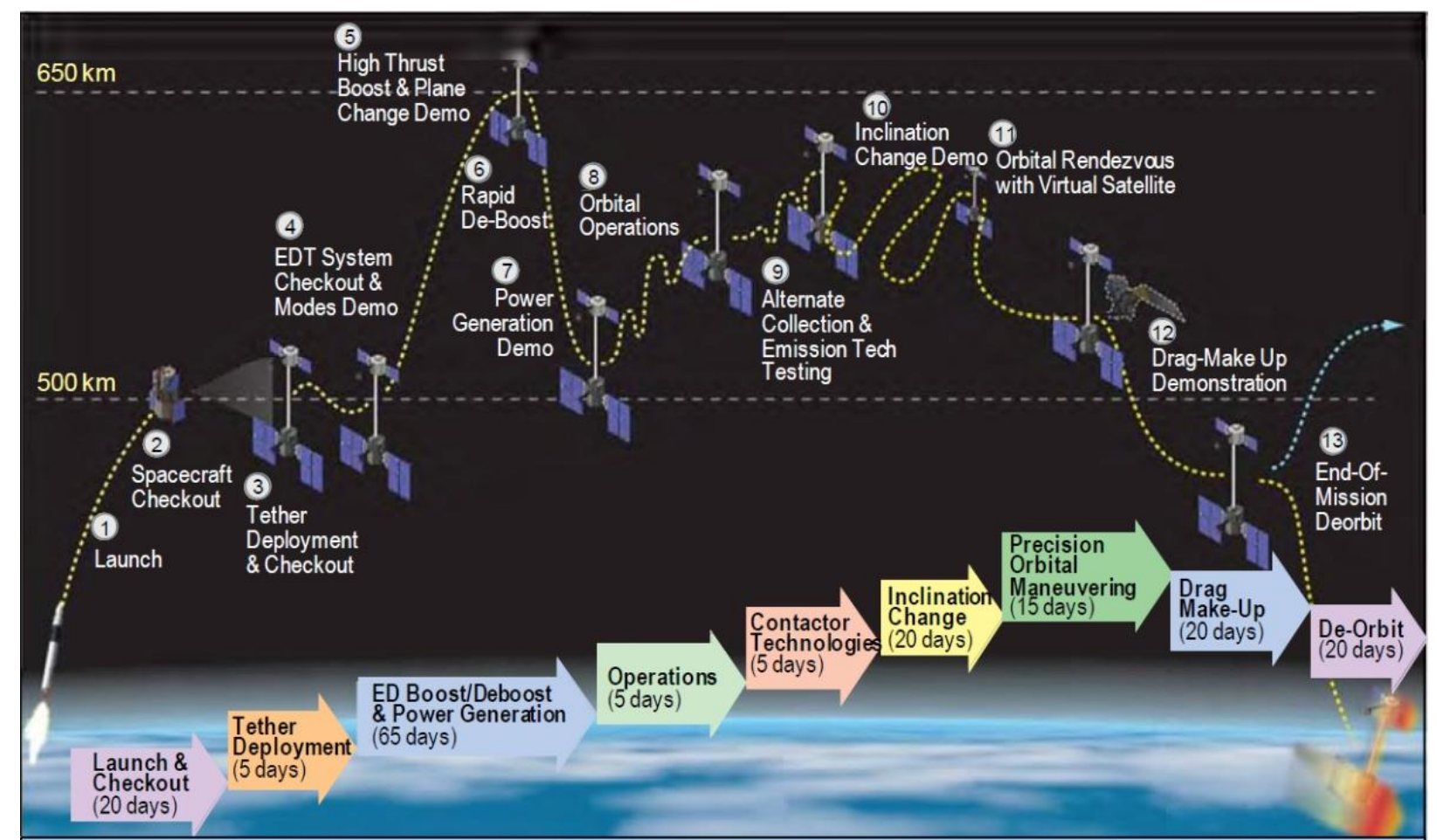

Figure 4. PROPEL's 6-month operational life will demonstrate all aspects of EDT propulsion and power generation capabilities in LEO. Description of mission events: (1) Rideshare launch to 500-km circular orbit; (2) Host and End Mass checkout prior to separation and tether deployment; (3) Controlled tether release and deployment; (4) Diagnostics on EDT tether and plasma environment, SV attitude control; (5) Orbit raising; (6\&7) Orbit lowering; (8) Orbital Maneuvering Tests; (9) Alternate collector/emitter demos; (10) Inclination change demonstration; (11) Autonomous trajectory profiling and rendezvous; (12) Orbit maintenance in high drag environment; and (13) Final de-orbit.

\section{Important EDT Questions to Advance Technology}

While fundamental aspects of EDT performance have been demonstrated during previous EDT missions as shown in Table A, there are important questions that deserve greater investigation for certain applications. Specifically, PROPEL is intended to advance the technology readiness level (TRL) for a propulsion system that can support a broad range of capabilities, e.g. boost, deboost, inclination change, drag make-up, and energy harvesting. This flexibility in contrast to an EDT system with more focused goals, e.g., only deorbit or drag make-up. Flexible orbital operations requires a system architecture with an appropriate level of symmetry to enable current flow in both directions (i.e., boost and deboost). For a bi-directional current configuration and to achieve the mission goals for PROPEL as outlined in Section III, we have identified several key questions pertaining to tether electrodynamics to be addressed during the PROPEL mission as discussed below. ${ }^{1}$ We note there are also equally important tether dynamics questions, not discussed here, that must be considered to fully advance the TRL level of an EDT system.

\section{A. Electrodynamics}

1. Measuring hollow-cathode plasma contactor performance

To enable bi-directional tether current flow, the PROPEL mission will use hollow-cathode plasma contactor (HCPC) devices placed at each end of the tether with one emitting electron current and the other collecting electron current. We thus need to adequately understand HCPC performance in the ionosphere and ask: What is the predictable performance of a HCPC to collect current from and emit current to the surrounding ionosphere 
in terms of tether current, HCPC parameters, and ionospheric conditions? The motivation for establishing a clear answer to this question results from our present understanding of HCPC operation in the ionosphere.

Over at least the last 25 years, there have been numerous studies and ground chamber tests of HCPCs for high current performance in both electron collection and emission modes. ${ }^{9,10}$ What is missing is definitive, in-space, high-current HCPC experiments to clarify actual performance in connecting current flow between the EDT system and the ionosphere. We focus on the electron collection process as it is generally believed to represent the largest effective impedance (as compared to electron emission). We cite two theoretical models to highlight the uncertainty. ${ }^{11}$ These models are thought to represent upper and lower bounds of electron-collection performance. The first was developed by Katz et al. ${ }^{12}$ and the second was proposed by Gerver et al. ${ }^{13}$ Because of differences between the two models, the Gerver et al. model tends to predict higher collected electron current for a given emitted ion current level, HCPC bias voltage, and ionospheric condition.

\section{Performance as a function of increasing tether current}

The TSS-1R mission demonstrated an ability to draw currents that reached just over $1 \mathrm{~A}$ in a system where the tether may have been the dominant impedance element in the overall tether circuit. ${ }^{14}$ However, for propulsion applications, the tether impedance will be much lower and tether currents of several amps or more will be required. We thus ask: How does EDT system performance change with increasing current (above 1 A) and how can the system be optimized for high current operation?

For low power applications (such as the PMG mission), the tether end bodies operate in the thermal current regime. Prior to the TSS missions, this regime was thought to be adequately described by the Parker-Murphy (PM) model. ${ }^{15}$ However, TSS measurements found PM current collections predictions to be too low by a factor of 2-3. An ad hoc modification to the PM model agrees with the TSS data but, since the exact physical mechanism is still unknown, the ad hoc correction may not hold under more general, and higher current, conditions.

When current is pushed above the level that can be provided by thermal currents at the plume double-layer boundary, tether endbody potential relative to the ambient ionosphere must increase more rapidly (increasing impedance). It is possible in this situation for additional plasma to also be generated by ionization of (un-ionized) gas from the HCPC, spacecraft out-gassing or sputter products, or ambient neutrals (in LEO, neutrals are 1000x denser than electrons). It is critical to determine the amount and source of any anomalous ionization. No EDT system has ever operated in this regime. PROPEL will operate in both the lower power regime described above as well as this higher power regime. Correspondingly, if EDTs are to be used for more ambitious missions in which higher thrust and power are required (e.g., ISS reboost or a MXER facility ${ }^{16}$ ), then it is essential that this regime be explored.

\section{B. EDT Operations}

It is not unreasonable to compare EDT maneuvering (e.g., boost, deboost, inclination change, drag make-up) to sailing a boat. For a sailboat, one can only go where and how the wind allows! Similarly, for an EDT system, it only can be maneuvered where and how the planetary magnetic field, ionosphere, and atmosphere allow. Predictable flight operations, i.e., getting from Point A to Point B, therefore will depend on an appropriate level of space weather forecasting, real-time observations, performance prediction, and integrated simulation. A general maneuvering strategy likely will depend initially on larger, less precise maneuvers followed by smaller, more precise maneuvers. Thus, with the PROPEL mission we will seek to answer: What level of forecasting, real-time observation, performance prediction, and integrated simulation are required to enable safe EDT system maneuvering?

\section{PROPEL Electrodynamic Measurement Goals}

The measurements required to properly address the questions pertaining to the tether electrodynamics identified above are overviewed below. In terms of understanding the electrodynamic state of the system (e.g., tether current, HCPC plasma plume, electrodynamic force, etc.) we can divide measurements into two groups: (1) those that measure the internal parameters of the (hard-wire) electrical circuit (e.g., the current flow in and voltage drop across the tether) and (2) those that determine the external leg of the circuit (e.g., the voltage drop and current flow between each tether end and the surrounding ambient ionosphere). As in any electrical circuit loop, current flow in the tether depends on the characteristics of the whole tether series circuit-including the distributed, external return current leg connecting with the ionosphere. Here, we focus on the electrodynamic measurements addressing the external leg of the circuit with measurements described below. 


\section{Characterization of ambient ionosphere}

Understanding the ambient environment is essential to establishing the local plasma parameters around the tether ends where current collection and emission take place. The most spatially and temporally variable parameters will be ionospheric plasma density (charge neutrality assumed) and electron temperature. In general, while understanding the neutral atmosphere make-up and density, as well as the ambient magnetic field, is essential, this information can be obtained via models. For tether lengths of several to ten or so kilometers, knowledge of ambient conditions at one end is adequate for understanding the environment at both ends, at least for quiet conditions. Concerns for strong vertical gradients, for example due to equatorial plasma bubbles, may require ambient measurements at both ends.

\section{Characterization of current flow at tether collecting/emitting ends}

In the presence of HCPC dense plasma plume emissions (which includes un-ionized gas from the HCPC), the environment around both tether ends is highly disturbed. The effective impedance between the ionosphere and the tether endbodies is also expected to be nonlinear as a function of tether current. Quantifying the HCPC plume, how it interacts with the ambient ionosphere, and identifying possible anomalous ionization effects under varying conditions will all be valuable information. This disturbed (non-Maxwellian) plasma environment will be highly localized and will have complex flow depending on source locations, magnetic field direction, and spacecraft velocity direction. Under this situation, knowledge of plasma density, electron and ion velocity distribution, potentials with respect to the spacecraft and ambient plasma, and neutral density composition are required for a complete assessment of the state and processes at both tether ends.

To properly understand the ambient and disturbed plasma states at the tether ends a combination of surface mounted and boom-mounted sensors will provide the necessary measurements. Figure 3 shows a boom placed on both tether spacecraft end-bodies. The boom is intended to provide a position that provides a direct measure of the ambient ionosphere and also "looks" both out and inward towards the spacecraft. Combined with spacecraft surface-mounted sensors that look out, a more complete picture of the complex interactions at both tether ends should be possible.

\section{Ongoing PROPEL Mission Design Efforts}

PROPEL was designed for versatility of the EDT system with multiple end users in mind and to be flexible with respect to platform. In partnership with the NASA's Office of Chief Technologist (OCT) Game Changing Program, NASA Marshall Space Flight Center (MSFC) Leadership, and the MSFC Advanced Concepts Office, an effort is underway to develop a mission concept design for a near-term EDT propulsion flight validation mission. The Electrodynamic Tether Propulsion Study (ETPS) will define an EDT propulsion system capable of very large delta$\mathrm{V}$ for use on future missions developed by NASA, DoD, and commercial customers. The ETPS is exploring applications for boost or deboost of assets in LEO such as servicing missions to the International Space Station (ISS) and for power generation. To complement the NASA team, MSFC has executed a Small Business Innovative Research (SBIR) Phase 3 contract, led by Tethers Unlimited, Inc., to continue leveraging the tether community's accomplishments and the prior experience of subject matter experts.

To demonstrate the feasibility of an ETPS, the study will focus on a space demonstration mission concept design with configuration of a pair of tethered satellite busses, one of which is the Japanese H-II Transfer Vehicle (HTV). The HTV would fly its standard ISS resupply mission. When resupply mission is complete, the ISS reconfigures and releases the HTV to perform the EDT experiment at safe orbital altitudes below the ISS. Though the focus of this particular mission concept design addresses a scenario involving the HTV or a similar vehicle, the propulsion system's capability is relevant to a number of applications, as noted above. The spacecraft is designed for minimal impact to HTV systems and will occupy only a portion of the HTV's payload accommodation. (See Figure 5.) The ETPS will build on prior work on long-life, failure-resistant, conducting tethers and include an instrument suite with demonstrated heritage capable of performing necessary diagnostics to measure performance against predictions for a given system size (to be determined) and boost rate. 
Since the HTV is substantially more massive than the free-flyer concept detailed in Section III above, the system's power requirement was increased from $1 \mathrm{~kW}$ to $2 \mathrm{~kW}$. This precipitated a slight increase in tether size and solar array power capability. In this mission concept, upon completing its primary mission objectives and departing from ISS, the HTV proceeds to a distance designated to be outside of the ISS operational volume, at which point the tether system will be deployed below the HTV. While tethered to the HTV, an inspace demonstration of a fully operational ETPS will be executed to boost and deboost the system mass and demonstrate energy harvesting. The tether spacecraft will carry out a series of controlled spacecraft propulsion maneuvers with critical performance measurements taken by onboard diagnostic instrumentation to verify predicted performance. Upon accomplishing its mission, the ETPS will have demonstrated the steps necessary to advance the system level TRL to 7-8.

Fail-safe features are integrated into the system design. Tether retrieval is accomplished from the EM. The EM is deployed below the HTV. In the event of a catastrophic break in

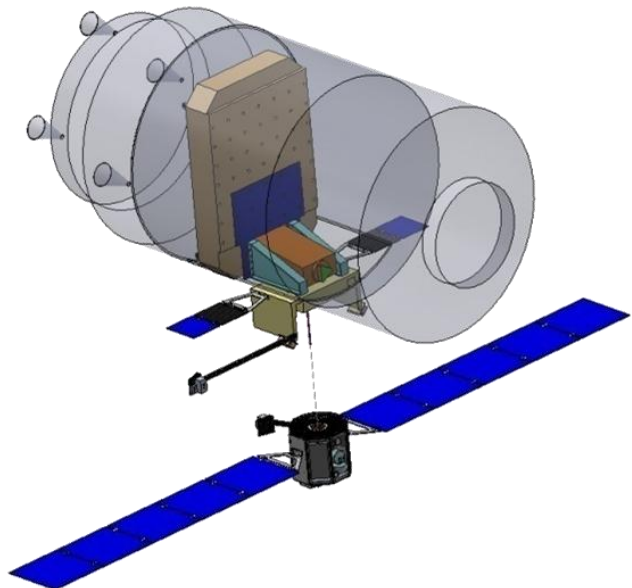

Figure 5. Design concept for PROPEL on the HTV.

the tether, the EM would have downward acceleration in a high drag region where it would re-enter rapidly and burn up. Momentum would be conserved, posing no risk and minimal movement for the HTV. The HTV also has its own propulsion system and can drive itself to a nominal reentry, if needed.

Ionospheric and magnetic field operational environmental models, expertise in plasma physics, and predictive modeling will be used to more accurately predict system and mission performance. The development of the Marshall Electrodynamic Tether Orbit Propagator (MEDTOP) is one of the primary products of this design effort. MEDTOP is a physics-based tool to model the EDT system performance and interactions in a space environment. This is a needed addition to the current suite of tools to simulate system performance.

The baseline concept design will include: mission and operation definition; identification and appropriate sizing of all components to be determined by analysis; baseline list of critical measurements to quantify performance; characterization of key technology risk; spacecraft bus design and system and integration requirements definition; and system safety impacts for manned systems. Given the proximity to other space assets, the demonstration mission concept is operationally very safe for ISS. The ISS community has provided data to determine sufficient altitude and clearance down and away from ISS for the ETPS demonstration. Aided by proprietary modeling techniques that include TUI's proprietary TetherSim software, ${ }^{2}$ end-to-end simulation of the tether system orbital dynamics will be used to evaluate mission requirements and demonstrate technical feasibility of the tether propulsion system. The tether propulsion system study will be completed prior to the end of FY12. Electrodynamic modeling on the MEDTOP tool will be complete in FY12 with updates to include the tether dynamics development continuing into FY13.

\section{Summary and Conclusion}

The PROPEL mission represents a significant effort to advance the TRL of EDT technology to an operational level. While the focus of this paper is principally on the "electrodynamics" of the system, the PROPEL mission itself addresses all aspects of an operational system, including dynamics, reliability, safety, operational planning, and external coordination. The PROPEL EDT system is being configured to validate operations associated with boost, deboost, inclination change, drag make-up, energy harvesting, and deorbit. A general mission configuration is discussed in Section III and a more specific alternate mission design is described in Section V, assuming the use of Japan's ISS HTV vehicle as the "host" spacecraft after its ISS-specific functions are completed.

The mission is being designed to quantify electrodynamic performance over a wide range of ambient conditions and thrust (tether current) levels. This includes specialized instrumentation to explore the connection between tether end-body spacecraft and the ambient ionosphere

\section{Appendix}

Space tether technology elements have been demonstrated on orbit over the past 30 years. In this timeframe, there have been over 23 major orbital/suborbital tether missions developed overall. A list of missions with which 
PROPEL team members have been involved along with the mission development timeline and key results is presented in Table A. These space tether missions typically can be divided into several key demonstration areas (electrodynamics/plasma physics, dynamics, or formation flying).

Table A. Selected tether missions of relevance to PROPEL. The PROPEL team has important connections to each of these missions.

\begin{tabular}{|c|c|c|c|}
\hline $\begin{array}{l}\text { Project Title and } \\
\text { Involved PROPEL Team } \\
\text { Members }\end{array}$ & Relevance to PROPEL & Launch Date & Tether Category and Mission Summary \\
\hline $\begin{array}{l}\text { Tether Experiment } \\
\text { (T-Rex) }\end{array}$ & $\begin{array}{l}\text { - Tether deployment } \\
\text { - Fast HCPC ignition }\end{array}$ & 31 August 2010 & $\begin{array}{l}\text { Electrodynamics/plasma physics } \\
+ \text { Successful deployment of tape and fast ignition } \\
\text { of hollow cathode }\end{array}$ \\
\hline $\begin{array}{l}\text { Multi-Application } \\
\text { Survivable Tether } \\
\text { (MAST) }\end{array}$ & - Tether dynamics & 17 April 2007 & $\begin{array}{l}\text { Dynamics } \\
\text { + Obtained data on tethered satellite dynamics } \\
\text { - Problem with release mechanism resulted in } \\
\text { minimal tether deployment }\end{array}$ \\
\hline $\begin{array}{l}\text { Propulsive Small } \\
\text { Expendable Deployer } \\
\text { System } \\
\text { (ProSEDS) }\end{array}$ & $\begin{array}{l}\text { - Hollow cathode plasma } \\
\text { contactor (HCPC), deflection } \\
\text { plate analyzer (DPA), and } \\
\text { Langmuir probe (LP) } \\
\text { instrument development } \\
\text { - Measurement device and model } \\
\text { development } \\
\text { - EDT heritage } \\
\text { - Tether development }\end{array}$ & 29 March 2003 & $\begin{array}{l}\text { Electrodynamics/plasma physics } \\
\text { + Model, process, and instrument development } \\
\text { - Did not launch because of changed NASA } \\
\text { requirements }\end{array}$ \\
\hline $\begin{array}{l}\text { Tether Physics and } \\
\text { Survivability Experiment } \\
\text { (TiPS) }\end{array}$ & $\begin{array}{l}\text { - Deployment } \\
\text { - Long-term survivability }\end{array}$ & $\begin{array}{l}\text { 12 May 1996- } \\
\text { 20 June } 1996 \\
\text { deploy }\end{array}$ & $\begin{array}{l}\text { Dynamics } \\
+ \text { Successful deployment } \\
+ \text { Tether survived over } 10 \text { years on orbit }\end{array}$ \\
\hline $\begin{array}{l}\text { Tethered Satellite System } \\
\text { Program Relight } \\
\text { (TSS-1R) }\end{array}$ & $\begin{array}{l}\text { - Current collection theory } \\
\text { - Tether deployment } \\
\text { - Plasma potential measurement } \\
\text { - EDT }\end{array}$ & $\begin{array}{l}22 \text { February- } \\
9 \text { March } 1996\end{array}$ & $\begin{array}{l}\text { Electrodynamics/plasma physics } \\
\text { + Demonstrated electrodynamic efficiency } \\
\text { exceeding existing theories } \\
\text { + Demonstrated ampere-level current } \\
\text { - Flaw in insulation allowed high-voltage arc to } \\
\text { cut tether } \\
\text { - Tether not tested prior to flight }\end{array}$ \\
\hline $\begin{array}{l}\text { Small Expendable } \\
\text { Deployer System } 2 \\
\text { (SEDS-2) } \\
\end{array}$ & $\begin{array}{l}\text { - Deployment and deboost } \\
\text { - EDT }\end{array}$ & 9 March 1994 & $\begin{array}{l}\text { Dynamics } \\
+ \text { Demonstrated successful, controlled deployment } \\
\text { of tether with minimal swing }\end{array}$ \\
\hline $\begin{array}{l}\text { Plasma Motor Generator } \\
\text { (PMG) }\end{array}$ & - Hollow cathode & 26 June 1993 & $\begin{array}{l}\text { Electrodynamics/plasma physics } \\
\text { + Demonstrated electrodynamic boost and } \\
\text { generator mode operation } \\
\text { - Did not measure thrust }\end{array}$ \\
\hline $\begin{array}{l}\text { Small Expendable } \\
\text { Deployer System } 1 \\
\text { (SEDS-1) }\end{array}$ & - Deployment and deboost & 29 March1993 & $\begin{array}{l}\text { Momentum exchange } \\
\text { + Demonstrated successful, stable deployment of } \\
\text { tether } \\
\text { + Demonstrated controlled deorbit of payload }\end{array}$ \\
\hline $\begin{array}{l}\text { First Tethered Satellite } \\
\text { System Program } \\
\text { (TSS-1) }\end{array}$ & $\begin{array}{l}\text { - Tether dynamics } \\
\text { - Controlled retrieval } \\
\text { - EDT }\end{array}$ & $\begin{array}{l}31 \text { July- } \\
8 \text { Aug1992 }\end{array}$ & $\begin{array}{l}\text { Electrodynamics/plasma physics } \\
\text { - Too-long bolt added without proper review } \\
\text { caused jam in tether deployer } \\
\text { + Demonstrated stable dynamics of short tethered } \\
\text { system } \\
\text { + Demonstrated controlled retrieval of tether }\end{array}$ \\
\hline CHARGE-2B & - High-voltage operations & 29 March 1992 & $\begin{array}{l}\text { Electrodynamics/plasma physics } \\
\text { + Full deployment of conductive tether } \\
\text { + Demonstration of active electron emission } \\
\text { + Demonstrated hollow cathode-like neutralizer }\end{array}$ \\
\hline CHARGE-2 & - High-voltage operations & 14 December 1985 & $\begin{array}{l}\text { Electrodynamics/plasma physics } \\
\text { + Full deployment of conductive tether } \\
\text { + Demonstration of active electron emission } \\
\text { + Demonstrated hollow cathode-like neutralization }\end{array}$ \\
\hline
\end{tabular}




\section{Acknowledgments}

We gratefully acknowledge support from the NASA George C. Marshall Space Flight Center.

\section{References}

${ }^{1}$ Gilchrist, B., Bilén, S., Hoyt, R., Stone, N., Vaughn, J., Fuhrhop, K., Khazanov, G., Krause, L., and Johnson, L., "The PROPEL Electrodynamic Tether Mission and Connecting to the Ionosphere," 12th Spacecraft Charging Technology Conference, Kitakyushu, Japan, 14-18 May 2012.

${ }^{2}$ Hoyt, R.P., "Propulsion and Power Harvesting Performance of Electrodynamic Tethers," AIAA Space 2011 Conf., AIAA 2011-7321, Long Beach, CA, 27-29 Sep 2011.

${ }^{3}$ Banks, P.M., "Review of Electrodynamic Tethers for Space Plasma Science," J. Spacecraft and Rockets, Vol. 26, No. 4, pp. 234-239, 1989.

${ }^{4}$ Sanmartín, J.R., Martinez-Sánchez, M., and Ahedo, E., "Bare Wire Anodes for Electrodynamic Tethers," J. Prop. and Power, Vol. 9, No. 3, pp. 353-360, 1993.

${ }^{5}$ Spindt, C., Macaulay, J., Barton, R., Cleeves, M., and Stanners, C., "Field Emission Cathode Performance in Thin CRTs," Vol. 508, B4.1/C5.2 (Materials Research Society, April 13-17, 1998, San Francisco, CA).

${ }^{6}$ Bilén, S.G., McTernan, J.K., Gilchrist, B.E., Bell, I.C., Voronka, N.R., and Hoyt, R.P., "Electrodynamic Tethers for Energy Harvesting and Propulsion on Space Platforms," AIAA-2010-8844, AIAA SPACE 2010 Conference \& Exposition, Anaheim, California, 30 August-2 September 2010.

${ }^{7}$ Hoyt, R. and Forward, R., "The Terminator Tether: Autonomous Deorbit of LEO Spacecraft for Space Debris Mitigation," AIAA Paper 00-0329, 38th AIAA Aerospace Sciences Conference, January 2000.

${ }^{8}$ Hoyt, R.P., Barnes, I.M., Voronka, N.R., and Slostad, J.T., "The Terminator Tape ${ }^{\text {TM}: ~ A ~ C o s t-E f f e c t i v e ~ D e-O r b i t ~ M o d u l e ~ f o r ~}$ End-of-Life Disposal of LEO Satellites,” AIAA Paper 2009-6733, Space 2009 Conference, Sept 2009.

${ }^{9}$ Wilbur, P.J. and Laupa, T., "Plasma Contactor Design for Electrodynamic Tether Applications," Adv. Space Res., Vol. 8, No. 1, pp. (1)221-(1)224, 1988.

${ }^{10}$ Kozakai, M. and Takegahara, H., "Evaluation of Plasma Contactor Ground Experiments for Electrodynamic Tether," $27^{\text {th }}$ Intl Elec. Prop. Conf., Pasadena, CA, IEPC 01-242, 15-19 Oct 2001.

${ }^{12}$ Katz, I., Lilley Jr., J., Greb, A., McCoy, J., Galofaro, J., and Ferguson, D.C., "Plasma Turbulence Enhanced Current Collection: Results from the Plasma Motor Generator Electrodynamic Tether Flight," J. Geophys. Res, Vol. 100, No. A2, pp. 1687-1690, Feb. 1995.

${ }^{13}$ Gerver, M.J., Hastings, D.E., and Oberhardt, M.R., "Theory of Plasma Contactors in Ground-Based Experiments and Low Earth Orbit," J. Spacecraft and Rockets, Vol. 27, No. 4, p. 391, July 1990.

${ }^{14}$ Stone, N. and Bonifazi , C., "The TSS-1R Mission: Overview and Scientific Context," Geophys. Res. Letters, Vol. 25, No. 4, pp. 409-412, Feb. 15, 1998.

${ }^{15}$ Parker, L.W. and Murphy, B.L., "Potential Build-up on an Electron Emitting Ionospheric Satellite," J. Geophys. Res., Vol. 72, p. 1631, 1967.

${ }^{16}$ Hoyt, R.P., Slostad, J.T., Frank, Scott S., and Voronka, N.R. "Momentum-Exchange/Electrodynamic Reboost (MXER) Tethers for Low-Cost Orbit Transfer," 52nd Joint Army, Navy, NASA, Air Force (JANNAF) Propulsion Meeting, Las Vegas, NV, 12-13 May 2004. 